$\begin{gathered}\text { Науковий вісник НлтУ України } \\ \text { Scientific Bulletin of UNFU } \\ \text { https://nv.nltu.edu.ua } \\ \text { https://doi.org/10.15421/40280603 } \\ \text { Article received 15.06.2018 p. } \\ \text { Article accepted 25.06.2018 p. } \\ \text { УДк 630*[521.1+174.752](477.87) }\end{gathered}$
$\begin{array}{r}\text { Correspondence author } \\ \text { B. Z. Nagorniak }\end{array}$
ISSN 1994-7836 (print)
bnahornjak@gmail.com

Б. З. Нагорняк

Національний лісотехнічний університет України, м. Львів, Украйна

\title{
БІОМЕТРИЧНІ ОЗНАКИ ТАКСАЦІЙНОЇ БУДОВИ ЗА ДІАМЕТРОМ ЯЛИЦЕВИХ ДЕРЕВОСТАНІВ ЗАКАРПАТТЯ
}

Проаналізовано літературні джерела з проблематики дослідження таксаційної будови насаджень в Україні та за ії межами. Розглянуто питання, пов'язані $з$ дослідженням біометричних ознак будови ялицевих деревостанів Закарпаття за діаметром у різних вікових групах. На підставі аналізу матеріалів 119 кругових пробних площ на території Закарпатського обласного управління лісового та мисливського господарства наведено аналіз біометричних ознак (середнього значення, основного відхилення, коефіцієнтів варіації, точності досліду, асиметрії та ексцесу) рядів розподілу дерев ялиці білої за діаметром та розподілу дерев за природними ступенями товщини у зв'язку з віковою зміною середніх діаметрів. З'ясовано, що серед усіх функцій, які використано у цих дослідженнях, найточніше будову ялицевих деревостанів за діаметром моделює функція Вейбулла. Здійснено перевірку узгодженості фактичних і теоретичних чисельностей за критерієм згоди Пірсона. За допомогою функції Вейбулла визначено теоретичні чисельності за ступенями товщини. На основі трипараметричної функції Вейбулла опрацьовано математичну модель рядів розподілу дерев за діаметром та віковими групами. Встановлено, що для будови ялицевих деревостанів Закарпаття за ступенями товщини характерне значне варіювання їхніх біометричних показників. Внаслідок виконаних досліджень побудовано узагальнені ряди розподілу дерев за діаметром, що є основою для подальшого розроблення нормативів товарної структури деревостанів.

Ключові слова: ялиця біла; будова за діаметром; ступені товщини; функція Вейбулла.

Вступ. У лісових насадженнях дерева постійно взаємодіють між собою. Такий зв'язок показує, як залежать окремі таксаційні показники один від одного. Під такою залежністю розуміють таксаційну будову насаджень (Horoshko, Myklush \& Khomiuk, 2004; Tsuryk, 2001). Закономірності розподілу дерев за ступенями товщини є основою будови деревостанів і використовуються для вирішення таких важливих питань, як складання товарних та інших лісотаксаційних таблиць, проектування лісогосподарських заходів тощо.

Вплив біотичних та антропогенних чинників на ліси загалом та ялицеві деревостани зокрема зумовлює певні особливості їх росту та розвитку. Складність вивчення будови ялицевих деревостанів за діаметром полягає у наявності цілого комплексу факторів, які впливають на розподіл частки дерев: типи лісорослинних умов, породний склад, вік, повнота, форма деревостану, лісогосподарська діяльність, екологічний стан, вітровали тощо.

Перші наукові праці, які стосуються будови насаджень, опубліковано у Німеччині у 1980 р. проф. В. Вейзе. Пізніше закономірності таксаційної будови за діаметром та іншими таксаційними показниками досліджували А. Шіффель, Н. С. Нестеров, Г. Р. Ейтинген, А. В. Тюрін, І. А. Кіщенко, Н. В. Третьяков, Л. І. Біцин, І. В. Весєлов, М. В. Давідов, Г. А. Ходот, О. І. Пітікін, П. Д. Марків, Л. Є. Рижило (Bitcin, 1965; Tretiakov, 1927; Goroshko et al., 1977).

Ялиця біла виступає як одна з основних лісотвірних порід на території Закарпаття. Щодо ялицевих природних і штучних лісів, то вивчення їх таксаційної будови привертало увагу багатьох учених, а зокрема: I. I. Молоткова, С. І. Цурик, В. П. Кичура, М. П. Горошко (Goroshko, 1978; Molotkova, 1965; Goroshko et al., 1977; Tsuryk, 2001).

Отже, метою роботи є дослідження біометричних особливостей таксаційної будови за діаметром ялицевих деревостанів Закарпаття, що дасть змогу змоделювати процеси росту цих насаджень та запроектувати відповідний режим ведення в них лісового господарства.

Матеріали та методи дослідження. Вихідною інформацією для дослідження таксаційної будови дерев ялиці білої слугували матеріали 119 кругових пробних площ різного віку, які ми заклали на території Закарпатського обласного управління лісового та мисливського господарства. Для необхідної достовірності отриманих результатів пробні площі закладали у різних лісництвах у ДП "Міжгірське", ДП "Великоберезнянське ЛГ", ДП "Рахівське ЛДГ" та ДП "Воловецьке ЛГ". Обсяг публікації не дає змоги подати їх детальну характеристику.

Результати дослідження та їх обговорення. Біометричний аналіз рядів діаметрів ялицевих деревостанів дослідних ділянок здійснено 3 використанням прийнятих у лісовій таксації стандартних методик (Ноroshko, Myklush \& Khomiuk, 2004).

Для моделювання розподілу ялицевих деревостанів

\section{Інформація про авторів:}

Нагорняк Богдан Зіновійович, асистент. Email: bnahornjak@gmail.com

Цитування за ДСтУ: Нагорняк Б. З. Біометричні ознаки таксаційної будови за діаметром ялицевих деревостанів Закарпаття. Науковий вісник НЛтУ України. 2018, т. 28, № 6. С. 18-22.

Citation APA: Nahornyak, B. Z. (2018). Biometric features of the diameter distribution structure of fir forests in Transcarpathia. Scientific Bulletin of UNFU, 28(6), 18-22. https://doi.org/10.15421/40280603 
за товщиною використано рівняння Вейбулла [4, 10], яке визначається трьома параметрами. Загальний вигляд такої функції описує формула

$$
F(x)=\frac{b}{a}\left(\frac{x-c}{a}\right)^{b-1} \operatorname{Exp}\left[-\left(\frac{x-c}{a}\right)\right],
$$

де: $a$ - параметр масштабу; $b$ - параметр форми; $c$ - параметр зсуву.

Трипараметрична функція Вейбулла характеризується високою пластичністю і найчастіше застосовується під час вивчення будови насаджень за діаметром. За різних значень параметрів функція описує весь діапазон неперервних кривих різної форми. Величини параметрів $a, b, c$ залежать від багатьох факторів, таких як вік, густота, тип лісу, лісогосподарських заходів, i відповідають певним характеристикам розподілу ряду діаметрів. Параметр зсуву а відповідає за нижню межу роз поділу (найменший діаметр), параметр масштабу $b$ - величину варіації розподілу (розмір кривої), а параметр форми с описує форму розподілу.

Результати біометричного опрацювання пробних площ рядів діаметрів подано в табл. 1. Аналіз біометричних показників вказує на належність вибірок до однієї вибіркової сукупності. Точність досліду знаходить- ся в межах $5 \%$, що свідчить про репрезентативність вибірок і можливість використання у подальших розрахунках.

Встановлено, що для ялицевих деревостанів регіону дослідження характерна значна мінливість біометричних показників діаметрів. Середній діаметр дерев на дослідних ділянках варіює в межах від 25,89 $35,34^{ \pm 1,69}$ см, а його основне відхилення - від 9,39 до 15,9 см. В усіх вікових групах спостерігається значна варіація. Коефіцієнт варіації змінюється в межах 34 43 \%. На відхилення від нормального розподілу вказують асиметрія та ексцес. Правостороннє відхилення від осі симетрії засвідчує коефіцієнт асиметрії, який перебуває в межах від $+0,15$ до +059 . Незначна і помірна ступінь косості кривої свідчить про велику концентрацію дерев навколо середнього значення, а також їх зосередження в нижчих ступенях товщини. Це можна пояснити систематичною вибіркою дерев 3 вищих ступенів товщини за інтенсивного ведення лісового господарства. Натомість значення ексцесу становить від 0,30 до-1,02, а це підтверджує туповершинність кривих розподілу за діаметром у всіх вікових групах.

Табл. 1. Біометричні показники ялицевих деревостанів Закарпаття

\begin{tabular}{|c|c|c|c|c|c|c|c|c|c|}
\hline \multicolumn{2}{|c|}{ Вікова група, роки } & $21-30$ & $31-40$ & $41-50$ & $51-60$ & $61-70$ & $71-80$ & $81-90$ & $91-100$ \\
\hline \multirow{2}{*}{$\begin{array}{c}\text { Середній ді- } \\
\text { аметр, } D_{1.3} \text { (см) }\end{array}$} & значення & 25,89 & 26,84 & 28,89 & 29,26 & 31,08 & 32,06 & 33,93 & 35,34 \\
\hline & помилка & 1,29 & 1,27 & 1,21 & 0,97 & 1,50 & 1,48 & 1,67 & 1,65 \\
\hline \multirow{2}{*}{$\begin{array}{l}\text { Стандартне від- } \\
\text { хилення, Ơ (см) }\end{array}$} & значення & 10,78 & 9,39 & 11,12 & 11,05 & 10,82 & 12,40 & 12,96 & 15,19 \\
\hline & помилка & 0,91 & 0,89 & 0,85 & 0,69 & 1,06 & 1,05 & 1,18 & 1,17 \\
\hline \multirow{2}{*}{$\begin{array}{l}\text { Коефіцієнт варі- } \\
\text { ації, V (\%) }\end{array}$} & значення & 41,66 & 34,98 & 38,47 & 37,76 & 34,82 & 38,68 & 38,18 & 42,99 \\
\hline & помилка & 4,09 & 3,72 & 3,36 & 2,65 & 3,81 & 3,73 & 3,96 & 3,86 \\
\hline \multirow{2}{*}{ Асиметрія, А } & значення & 0,21 & 0,23 & 0,19 & 0,33 & 0,15 & 0,39 & 0,59 & 0,32 \\
\hline & помилка & 0,29 & 0,33 & 0,27 & 0,21 & 0,34 & 0,29 & 0,32 & 0,27 \\
\hline \multirow{2}{*}{ Ексцес, Е } & значення & $-0,65$ & $-0,54$ & $-1,02$ & $-0,59$ & $-0,90$ & $-0,57$ & $-0,30$ & $-0,42$ \\
\hline & помилка & 0,59 & 0,66 & 0,53 & 0,43 & 0,68 & 0,59 & 0,63 & 0,53 \\
\hline \multirow{2}{*}{$\begin{array}{c}\text { Точність досліду, } \\
\text { Р (\%) }\end{array}$} & значення & 4,98 & 4,72 & 4,17 & 3,31 & 4,83 & 4,62 & 4,93 & 4,66 \\
\hline & помилка & 0,49 & 0,50 & 0,36 & 0,23 & 0,53 & 0,45 & 0,51 & 0,42 \\
\hline
\end{tabular}

Для виявлення закономірностей будови ялицевих насаджень та апроксимації розподілу чисельностей за діаметром використано моделі Грамма-Шарльє, Лапласа-Гауса, Пірсона, Пуасона і Вейбулла. Розрахунки проводилися за допрацьованими програмами в середовищі Microsoft Office Excel на кафедрі лісової таксації та лісовпорядкування НЛТУ України.

За результатами проведених обчислень здійснено перевірку узгодженості фактичних і теоретичних чисельностей за критерієм згоди Пірсона (Horoshko, Myklush \& Khomiuk, 2004). З'ясовано, що найточніше будову ялицевих деревостанів за діаметром моделює функція Вейбулла. Отже, теоретичні чисельності за ступенями товщини вирахували для цієї моделі розподілу (табл. 2). Графічну ілюстрацію розподілу кількості дерев за ступенями товщини показано на рис. 1.

Вирівнювання переліку дерев здійснене для усіх пробних площ, але на рис. 1-8 та у табл. 2 наведено результати оброблення, які репрезентують різні вікові групи.

Здійснивши аналіз наведених вище результатів досліджень, можна стверджувати, що таксаційна будова за діаметром ялицевих деревостанів відповідає характеру будови нормальних насаджень, але має свої особливості будови (Horoshko, Myklush \& Khomiuk, 2004; Goroshko, 1978; Tretiakov, 1927). Аналізуючи показники асиметрії та ексцесу, чіткої закономірності зміни із середнім діаметром не виявлено.

Спостерігається зосередження більшої кількості дерев у нижніх ступенях товщини. Також зі збільшенням середнього діаметра (і віку) проявляється певна тенденція до нормалізації розподілу дерев за товщиною, за винятком кількох вікових груп. Це можна пояснити посиленням відпаду дерев у старшому віці. Можна висловити припущення, що зменшення значення ексцесу та краще групування навколо середнього значення пов'язане з формуванням біогруп.

Аналізуючи дані будови за модельованими ступенями товщини, можна прослідкувати тенденцію до зменшення значень піку розподілу у віці 31-60 років. Це можна пояснити загальновідомими тенденціями росту ялицевих деревостанів. Кількість підросту, яка з віком переходить до намету деревостану, може бути причиною зміщення положення піку відносно центрального ступеня. Таке значне варіювання рядів діаметрів ялицевих деревостанів за біометричними показниками можна пояснити насамперед тим, що на процеси росту дерев у насадженнях, у яких відбирали польовий матеріал, впливають такі чинники, як стихійні природні явища, природні процеси відмирання дерев, лісогосподарська діяльність людини певної інтенсивності. 



Рис. 1. Графіки розподілу фактичної та теоретичної кількості дерев за ступенями товщини ялицевих деревостанів у віці: а) 21-30 років; б) 31-40 років; в) 41-50 років; г) 51-60 років; d) 61-70 років; e) 71-80 років; є) 81-90 років; ж) 91-100 років 
Табл. 2. Чисельності рядів розподілу на пробних площах за ступенями товщини

\begin{tabular}{|c|c|c|c|c|c|c|c|c|c|c|c|c|c|c|c|c|}
\hline \multirow{3}{*}{$\begin{array}{c}\text { Ступінь } \\
\text { товщи- } \\
\text { ни }\end{array}$} & \multicolumn{16}{|c|}{ Теоретичні чисельності, визначені за функцією Вейбулла, \% } \\
\hline & \multicolumn{2}{|c|}{ 21-30 років } & \multicolumn{2}{|c|}{$31-40$ років } & \multicolumn{2}{|c|}{ 41-50 років } & \multicolumn{2}{|c|}{ 51-60 років } & \multicolumn{2}{|c|}{$61-70$ років } & \multicolumn{2}{|c|}{ 71-80 років } & \multicolumn{2}{|c|}{$81-90$ років } & \multicolumn{2}{|c|}{ 91-100 років } \\
\hline & J & $i$ & $f$ & $i$ & $\bar{f}$ & $i$ & 1 & $i$ & J & $t$ & C & $i$ & J & $l$ & j & $t$ \\
\hline 8 & 7,14 & 4,73 & 1,82 & 1,86 & 1,18 & 2,94 & 1,54 & 2,17 & 0,00 & 1,28 & 0,00 & 1,56 & 0,00 & 0,51 & 2,35 & 2,32 \\
\hline 12 & 8,57 & 9,17 & 5,45 & 6,12 & 5,88 & 6,76 & 3,85 & 5,93 & 3,85 & 4,12 & 4,29 & 4,56 & 1,67 & 2,59 & 5,88 & 4,87 \\
\hline 16 & 11,43 & 11,82 & 12,73 & 10,54 & 14,12 & 9,60 & 11,54 & 9,25 & 9,62 & 7,18 & 10,00 & 7,49 & 6,67 & 5,82 & 4,71 & 6,59 \\
\hline 20 & 10,00 & 13,15 & 12,73 & 14,03 & 11,76 & 11,43 & 14,62 & 11,66 & 9,62 & 9,95 & 10,00 & 9,90 & 11,67 & 9,31 & 8,24 & 7,69 \\
\hline 24 & 12,86 & 13,40 & 14,55 & 15,79 & 10,59 & 12,27 & 11,54 & 12,91 & 11,54 & 12,03 & 11,43 & 11,47 & 10,00 & 12,06 & 9,41 & 8,44 \\
\hline 28 & 14,29 & 12,64 & 16,36 & 15,53 & 10,59 & 12,22 & 10,77 & 12,97 & 13,46 & 13,11 & 11,43 & 12,03 & 13,33 & 13,25 & 8,24 & 8,97 \\
\hline 32 & 12,86 & 11,11 & 12,73 & 13,46 & 11,76 & 11,45 & 11,54 & 12,04 & 11,54 & 13,05 & 10,00 & 11,68 & 11,67 & 12,63 & 9,41 & 9,34 \\
\hline 36 & 10,00 & 9,07 & 14,55 & 10,22 & 9,41 & 10,16 & 13,08 & 10,40 & 13,46 & 11,94 & 12,86 & 10,59 & 13,33 & 10,71 & 9,41 & 9,51 \\
\hline 40 & 5,71 & 6,80 & 1,82 & 6,65 & 10,59 & 8,53 & 6,92 & 8,39 & 9,62 & 10,00 & 8,57 & 9,01 & 6,67 & 8,42 & 9,41 & 9,31 \\
\hline 44 & 2,86 & 4,58 & 3,64 & 3,56 & 7,06 & 6,70 & 6,15 & 6,29 & 7,69 & 7,61 & 5,71 & 7,21 & 6,67 & 6,51 & 8,24 & 8,61 \\
\hline 48 & 2,86 & 2,63 & 3,64 & 1,46 & 4,71 & 4,76 & 6,15 & 4,29 & 3,85 & 5,16 & 7,14 & 5,42 & 5,00 & 5,21 & 8,24 & 7,35 \\
\hline 52 & 43 & 1,13 & 0,00 & 0,42 & 2,35 & 2,82 & 0,77 & 2,51 & 5,77 & 3,02 & 4,29 & 3,83 & 5,00 & 4,27 & 5,88 & 5,73 \\
\hline 56 & 00 & 0,15 & 0,00 & 0,11 & 0,00 & 1,08 & 0,77 & 1,05 & 0,00 & 1,41 & 1,43 & 2,52 & 3,33 & 3,39 & 2,35 & 4,06 \\
\hline 60 & 0,00 & $-0,32$ & 0,00 & 0,09 & 0,00 & $-0,18$ & 0,77 & 0,10 & 0,00 & 0,42 & 1,43 & 1,53 & 1,67 & 2,44 & 3,53 & 2,66 \\
\hline 64 & 0,00 & $-0,41$ & 0,00 & 0,08 & 0,00 & $-0,69$ & 0,00 & $-0,19$ & 0,00 & $-0,05$ & 1,43 & 0,85 & 1,67 & 1,53 & 2,35 & 1,66 \\
\hline 68 & 0,00 & $-0,29$ & 0,00 & 0,05 & 0,00 & $-0,51$ & 0,00 & $-0,04$ & 0,00 & $-0,16$ & 0,00 & 0,41 & 1,67 & 0,81 & 0,00 & 1,03 \\
\hline 72 & 0,00 & $-0,11$ & 0,00 & 0,02 & 0,00 & $-0,06$ & 0,00 & 0,10 & 0,00 & $-0,11$ & 0,00 & 0,15 & 0,00 & 0,36 & 1,18 & 0,66 \\
\hline 76 & 0,00 & 0,04 & 0,00 & 0,01 & 0,00 & 0,19 & 0,00 & 0,09 & 0,00 & $-0,04$ & 0,00 & 0,02 & 0,00 & 0,13 & 1,18 & 0,43 \\
\hline 80 & 0,00 & 0,12 & 0,00 & 0,00 & 0,00 & 0,20 & 0,00 & 0,05 & 0,00 & 0,01 & 0,00 & $-0,04$ & 0,00 & 0,04 & 0,00 & 0,28 \\
\hline 84 & 000 & 0,14 & 0,00 & 0 & 0,00 & 0,13 & 0,00 & 0,02 & 0,00 & 0,02 & 0,00 & $-0,05$ & 0,00 & 0,01 & 0,00 & 0,18 \\
\hline 88 & 0,00 & 0,12 & 0,00 & 0,00 & 0,00 & 0,08 & 0,00 & 0,01 & 0,00 & 0,02 & 0,00 & $-0,05$ & 0,00 & 0,00 & 0,00 & 0,11 \\
\hline 92 & 0,00 & 0,09 & 0,00 & 0,00 & 0,00 & 0,04 & 0,00 & 0,00 & 0,00 & 0,01 & 0,00 & $-0,04$ & 0,00 & 0,00 & 0,00 & 0,07 \\
\hline 96 & 0,00 & 0,06 & 0,00 & 0,00 & 0,00 & 0,02 & 0,00 & 0,00 & 0,00 & 0,00 & 0,00 & $-0,03$ & 0,00 & 0,00 & 0,00 & 0,04 \\
\hline 100 & 0,00 & 0,04 & 0,00 & 0,00 & 0,00 & 0,01 & 0,00 & 0,00 & 0,00 & 0,00 & 0,00 & $-0,02$ & 0,00 & 0,00 & 0,00 & 0,02 \\
\hline 104 & 0,00 & 0,02 & 0,00 & 0,00 & 0,00 & 0,01 & 0,00 & 0,00 & 0,00 & 0,00 & 0,00 & $-0,01$ & 0,00 & 0,00 & 0,00 & 0,01 \\
\hline 108 & 0,00 & 0,01 & 0,00 & 0,00 & 0,00 & 0,00 & 0,00 & 0,00 & 0,00 & 0,00 & 0,00 & $-0,01$ & 0,00 & 0,00 & 0,00 & 0,01 \\
\hline 112 & 0,00 & 0,01 & 0,00 & 0,00 & 0,00 & 0,00 & 0,00 & 0,00 & 0,00 & 0,00 & 0,00 & 0,00 & 0,00 & 0,00 & 0,00 & 0,00 \\
\hline Сума & 100 & 100 & 100 & 100 & 100 & 100 & 100 & 100 & 100 & 100 & 100 & 100 & 100 & 100 & 100 & 100 \\
\hline$a$ & & 3,56 & & 3,56 & & 3,56 & & 3,56 & & 3,56 & & 3,56 & & 3,56 & & 3,56 \\
\hline 6 & & 29,23 & & 25,86 & & 29,92 & & 28,17 & & 32,68 & & 31,33 & & 25,85 & & 30,76 \\
\hline $\mathrm{c}$ & & 1,72 & & 2,31 & & 1,89 & & 2,09 & & 2,26 & & 2,16 & & 2,83 & & 1,79 \\
\hline
\end{tabular}

Примітка: $f$ - фактичні дані рядів розподілу; $t$ - теоретичні дані рядів розподілу; $a, b, c$ - параметри розподілу функції Вейбулл

Висновки. Для будови ялицевих деревостанів Закарпаття за ступенями товщини характерне значне варіювання їхніх біометричних показників. Для апроксимування розподілів діаметрів таких насаджень доцільно застосовувати трипараметричну функцію розподілу Вейбулла. Це може бути використано для проектування низки екологічно нешкідливих лісогосподарських заходів під час формування корінних, біологічно стійких, продуктивних i високотоварних ялицевих насаджень цього регіону.

Подяка. Автор висловлює подяку науковому керівнику завідувачу кафедри лісової таксації та лісовпорядкування Національного лісотехнічного університету України проф. кафедри М. П. Горошку за керівництво та надану допомогу під час написання статті.

\section{Перелік використаних джерел}

Bitcin, L. V. (1965). Stroenie i produktivnost gornykh lesov. Moscow: Lesn. prom-st. 128 p. [In Russian].

Horoshko, M. P., Myklush, S. I., \& Khomiuk, P. H. (2004). Biometriia. Lviv: "Kamula". 236 p. [In Ukrainian].

Goroshko, M. P. (1978). Osobennosti stroeniia, rost i perspektivy iskusstvennykh pikhtarnikov Ukrainskikh Karpat. Abstract of
Doctoral Dissertation for Agricultural Sciences (06.03.03 - Silvics and forestry). Leningrad. 26 p. [In Ukrainian].

GOST II.007-75. (1976). Pravila opredileniia otcenok i doveritelnykh granitc dlia parametrov raspredileniia Veibula. Moscow: Gosstandart. [In Russian].

Molotkova, I. I. (1965). Stroenie, biologiia i sortimentnaia struktura estestvennykh pikhtovykh nasazhdenii Zakarpatia. Abstract of Doctoral Dissertation for Agricultural Sciences (06.03.02 - Forest management and forest taxation). Kharkov. 23 p. [In Russian].

Goroshko, M. P., Kichura, V. P., Feliv, A. A., Chornyi, O. S., Kucheriavyi, V. A. (1977). Stroenie, khod rosta i dinamika tovarnoi strukturydrevostoev osnovnykh lesoobrazuiushhikh porod po tipam lesa $i$ s lesovodstvennym raionirovaniem: metodicheskie rekomendatcii dlia lesoustroistva na tipologicheskoi osnove. (in Ya. A. Saban ed.). Lviv: Vid-vo LLTI. 104 p. [In Russian].

Shvidenko, A. I. (1980). Pikhtovye lesa Ukrainy. Lvov: Vysshaia shkola. 192 p. [In Russian].

Tretiakov, N. V. (1927). Zakon edinstva $v$ stroenii nasazhdenii. Moscow-Leningrad: Novaia derevnia. 113 p. [In Russian].

Tsuryk, Ye. I. (2001). Taksatsiini oznaky y budova nasadzhennia. Lviv: UkrDLTU. 362 p.

Bailey, R. L., \& Dell, T. R. (1973). Quantifying diameter distribution with the Weibull funktion. Forest Sciense, 19, 97-104.

Национальный лесотехнический университет Украины, г. Львов, Украина БИОМЕТРИЧЕСКИЕ ПРИЗНАКИ ТАКСАЦИОННОГО СТРОЕНИЯ ПО ДИАМЕТРУ ПИХТОВЫХ ДРЕВОСТОЕВ ЗАКАРПАТЬЯ

Проанализированы литературные источники по проблематике исследования таксационного строения насаждений в Украине и за ее пределами. Рассмотрены вопросы, связанные с исследованием биометрических признаков строения пихтовых древостоев Закарпатья по диаметру в разных возрастных группах. На основании анализа материалов 119 круговых пробных площадей на территории Закарпатского областного управления лесного и охотничьего хозяйства приведен анализ биометрических признаков (среднего значения, основного отклонения, коэффициентов вариации, точности опыта, асимметрии и 
эксцесса) рядов распределения деревьев пихты белой по диаметру и распределения деревьев по природным степенями толщины в связи с возрастным изменением средних диаметров. Выяснено, что среди всех функций, которые были использованы в данных исследованиях, точно строение пихтовых древостоев по диаметру моделирует функция Вейбулла. Осуществлена проверка согласованности фактических и теоретических численностей по критерию согласия Пирсона. С помощью функции Вейбулла определены теоретические численности по ступеням толщины. На основе трипараметричной фунции Вейбулла обработана математическая модель рядов распределения деревьев по диаметру и возрастным группам. Установлено, что для строения пихтовых древостоев Закарпатья по ступеням толщины характерно значительное варьирование их биометрических показателей. Вследствие выполненных исследований построены обобщенные ряды распределения деревьев по диаметру, что является основой для дальнейшей разработки нормативов товарной структуры древостоев.

Ключевые слова: пихта белая; строение по диаметру; степени толщины; функция Вейбулла.

B. Z. Nahornyak

Ukrainian National Forestry University, Lviv, Ukraine

\section{BIOMETRIC FEATURES OF THE DIAMETER DISTRIBUTION STRUCTURE OF FIR FORESTS IN TRANSCARPATHIA}

The regularities of the structure according to the thickness classes is the basis of the structure of the stands and is used for solving such important issues as the compilation the commodity and other forest-mensuration tables, planning the forest management etc. The history of the research of mensuration structure of stands in Ukraine and abroad has been analyzed according to the literary sources. The questions related to the researches of biometric features of the structure by diameter in different age groups of the fir tree stands of Transcarpathia are considered. The source information for the study of the mensuration structure of the white fir were materials of 119 circular test plots of different ages that were laid on the territory of the Transcarpathian Regional Department of Forestry and Hunting. For greater reliability of the obtained results, test plots were laid in different forestries of the Mizhhirya, Great Berezne, Rakhiv, Volovets State Forestry Enterprise. Biometric analysis ranks of diameters of fir tree stands in experimental areas was carried out using standard methods adopted in forest mensuration. An analysis of the biometric characteristics, based on the analysis of materials of test plots (average value, basic deviation, coefficients of variation, accuracy of the experiment, asymmetry and excess) of the diameter distribution of white fir trees and the distribution of trees by natural thickness ranks in connection with the age variation of the average diameters. It was found out that among all the functions that were used in these studies to model diameter mensuration structure, the most accurate results showed the Weibull function. Pearson's consent criterion was used for verification the consistency of the actual and theoretical numbers. The theoretical numbers of thickness classes were determined with the help of the Weibull function. On the basis of the three-parameter Weibull function, a mathematical model of trees distribution by diameter and age groups was worked out. It has been proved that diameter distribution structure of fir stands in Transcarpathia, is characterized by a significant variation of their biometric indices. As a result of the performed research, generalized ranks of diameter distribution of trees are constructed, which is the basis for further development of the standards of the commodity structure of forest stands.

Keywords: white fir; diameter structure; thickness classes; Weibull function. 